\title{
Evolution of Reptilian Visual Systems: Retinal Projections in a Nocturnal Lizard, Gekko gecko (Linnaeus)
}

\author{
R. GLENN NORTHCUTT AND ANN B. BUTLER I \\ Department of Zoology, University of Michigan, Ann Arbor, Michigan \\ 48104 and Department of Neurological Surgery, University of \\ Virginia School of Medicine, Charlottesville, Virginia 22901
}

\begin{abstract}
On the basis of the development of the dorsal ventricular ridge of the telencephalon, lizards can be divided into a type I group, to which Gekko and the majority of lizard families belong, and a type II group with more derived features, of which Iguana is representative. Most studies of retinal projections have utilized lizards of the type II group, which are adapted to a diurnal niche. Gekko gecko is differently adapted in that it is nocturnal. Study of the retinal projections was undertaken in Gekko gecko in order to insure that conclusions regarding the pattern of retinal pathways in saurians would be based on a sample which was more representative of the total range of variation.

Unilateral removal of the retina by suction cannula was carried out on 12 adult specimens of Gekko gecko. After survival times of 10 to 74 days, brains were processed with various silver methods. The retina projects contralaterally to the pars dorsalis and pars ventralis of the lateral geniculate nucleus and the pars ventralis of the ventrolateral nucleus in the thalamus, nuclei geniculatus pretectalis, Ientiformis mesencephali, and posterodorsalis in the pretectum, layers 8-14 of the optic tectum, and nucleus opticus tegmenti. Additionally, the retina projects ipsilaterally to the dorsal and ventral lateral geniculate nuclei and to the pretectal nuclei, as well as to the optic tectum, particularly layers 8 and 9.

The finding of ipsilateral retinothalamic projections in Gekko supports the idea that this pathway is generalized among saurians. However, presence of ipsilateral retinothalamic projections and the degree of binocular overlap cannot be correlated when lizards, snakes, crocodiles, and turtles are compared. The functional significance of this pathway therefore remains obscure. Ipsilateral retinotectal projections have not been previously described in land vertebrates other than mammals. Whether their presence is correlated with nocturnal visual habits or is generalized among type I lizards remains to be determined. The pattern of retinal projections has been studied in too few representatives of non-mammalian land vertebrates to presently permit conclusions regarding the origin of non-decussating pathways.
\end{abstract}

Among lizards there is a broad range of morphological variation for a number of brain characters. Cross-sections at corresponding mid-telencephalic levels of the brains of two lizards, Gekko gecko and Iguana iguana, are compared in figure 1. They are representative of two different major groups of lizards, which can be separated on the basis of the development of the dorsal ventricular ridge (Northcutt, '72). The first group, type I lizards, represented here by Gekko, includes such diverse families as feyliniids, scincids, lacertids, xantusids, anguids, and others.
The second group, type II lizards, represented here by Iguana, includes the teiids, varanids, agamids, iguanids, and chamaeleonids.

Of particular relevance to a consideration of the visual system are the striking differences in the morphology of the dorsal ventricular ridge (DVR) between these two types of lizards. Visual projections to the DVR, from the optic tectum via the dorsal thalamic nucleus rotundus, have

\footnotetext{
1 Present address: Department of Anatomy, The George Washington University, School of Medicine 2300 I St., N.W., W ashington, D.C. 20037.
} 
been demonstrated in several reptiles (Hall and Ebner, '70a,b; Braford, '72; Pritz, '73). Aspiration of the dorsal thalamus in Iguana (Butler and Ebner, '72) and Gekko (unpublished data) result in terminal degeneration in several discrete regions of the DVR; the most lateral region corresponds topographically to the locus of the rotundal input in the other reptiles studied.

As seen in figure 1, the dorsal ventricular ridge of Gekko is formed by a core nucleus surrounded by a corticoid band of cells. This type I DVR pattern is also found in Sphenodon (Cairney, '26; Durward, '30) and in turtles (Northcutt, '70), and probably represents the ancestral pattern of the reptilian DVR. This condition sharply contrasts to that seen in the type II lizards, represented in figure 1 by Iguana. In Iguana the DVR is composed of a number of nuclear groups and occupies a relatively larger portion of the telencephalon.

With the exception of Lacerta (Armstrong, '50), the studies to date on visual projections in lizards are restricted to members of the type II group (Ebbesson, '70a; Butler and Northcutt, '71). These lizards are not representative of the ancestral lacertilian stock (Camp, '23). Moreover, type II lizards are restricted to a single adaptive zone, which is a diurnal one.

The retinal projections described in type II lizards do not differ greatly from those described by Armstrong (50) in Lacerta. However, study of visual pathways in additional species of the more generalized type I lizards is important for two reasons. First, the Nonidez silver method used by Armstrong is less sensitive than the recent modifications of the Nauta silver impregnation method. Secondly, Lacerta is a terrestrial, diurnal predator, occupying a niche similar to that of the type II lizards; thus, the sample to date is not representative of the wide range of diversity in saurian niches.

The type I lizard, Gekko gecko, is arboreal, as are many of the type II iguanas and chameleons. However, in contrast to the latter, geckos are nocturnal predators. The work of Citron and Pinto (73) indicates that the structure of the gecko eye produces a larger and more illuminous retinal image than that of the iguanid

Abbreviations used in figures $1-5$

AT, area triangularis

$\mathrm{CP}$, cell plate of nucleus geniculatus pretectalis $\mathrm{D}$, dorsal cortex

DLH, nucleus dorsolateralis hypothalami

Dm, dorsal cortex, pars medialis

DM, nucleus dorsomedialis

DVR, dorsal ven tricular ridge

DVRc, dorsal ventricular ridge, core nucleus

DVRs, dorsal ventricular ridge, surrounding corticoid band

GP, nucleus geniculatus pretectalis

GLV, nucleus geniculatus lateralis pars ventralis

HC, habenular commissure

$\mathrm{Hd}$, nucleus habenularis pars dorsalis

$\mathrm{Hv}$, nucleus habenularis pars ventralis

$\mathrm{L}$, lateral cortex

LA, nucleus dorsolater alis anterior

LFB, lateral forebrain bundle

LFBd, dorsal peduncle of lateral forebrain bundle

LFBv, ventral peduncle of lateral forebrain bundle

$\mathrm{LH}$, nucleus lateralis hypothalami

LM, nucleus lentiformis mesencephali

LN, lateral neuropil of nucleus geniculatus lateralis pars ventralis

LOT, lateral optic tract

$M$, nucleus medialis

MC, medial cell plate of nucleus geniculatus lateralis pars ventralis

MFB, medial for ebrain bundle

$\mathrm{Ml}$, medial cortex, pars lateralis

Mm, medial cortex, pars medialis
MOT, medial optic tract

NOT, nucleus opticus tegmenti

NPD, nucleus posterodorsalis

NS, nucleus sphericus

OT, optic tract

$P$, nucleus periventricularis hypothalami

$\mathrm{PD}$, nucleus geniculatus lateralis pars dorsalis

$\mathbf{P E}$, nucleus lentiformis thalami pars extensa.

PP, nucleus lentiformis thalami pars plicata

$\mathbf{R}$, nucleus rotundus

$\mathrm{S}$, septum

SC, suprachiasmatic nucleus

SM, stria medullaris

SO, subcommissural organ

SON, supraoptic nucleus

ST, striatum

$V$, lateral ventricle

Vd, nucleus ventrolateralis pars dorsalis

$\mathrm{VH}$, nucleus ventralis hypothalami

VM, nucleus ventromedialis of the thalamus

VMt, nucleus ventromedialis of the telencephalon

$\mathrm{Vv}$, nucleus ventrolateralis pars ventralis 1 , layer 1 of Ramón of the optic tectum

1-5, layers 1-5 of Ramón of the optic tectum

3-7, layers 3-7 of Ramón of the optic tectum

5 , layer 5 of Ramón of the optic tectum

6 , layer 6 of Ramón of the optic tectum

7 , layer 7 of Ramón of the optic tectum

8-14, layers 8-14 of Ramón of the optic tectum III, third ventricle 

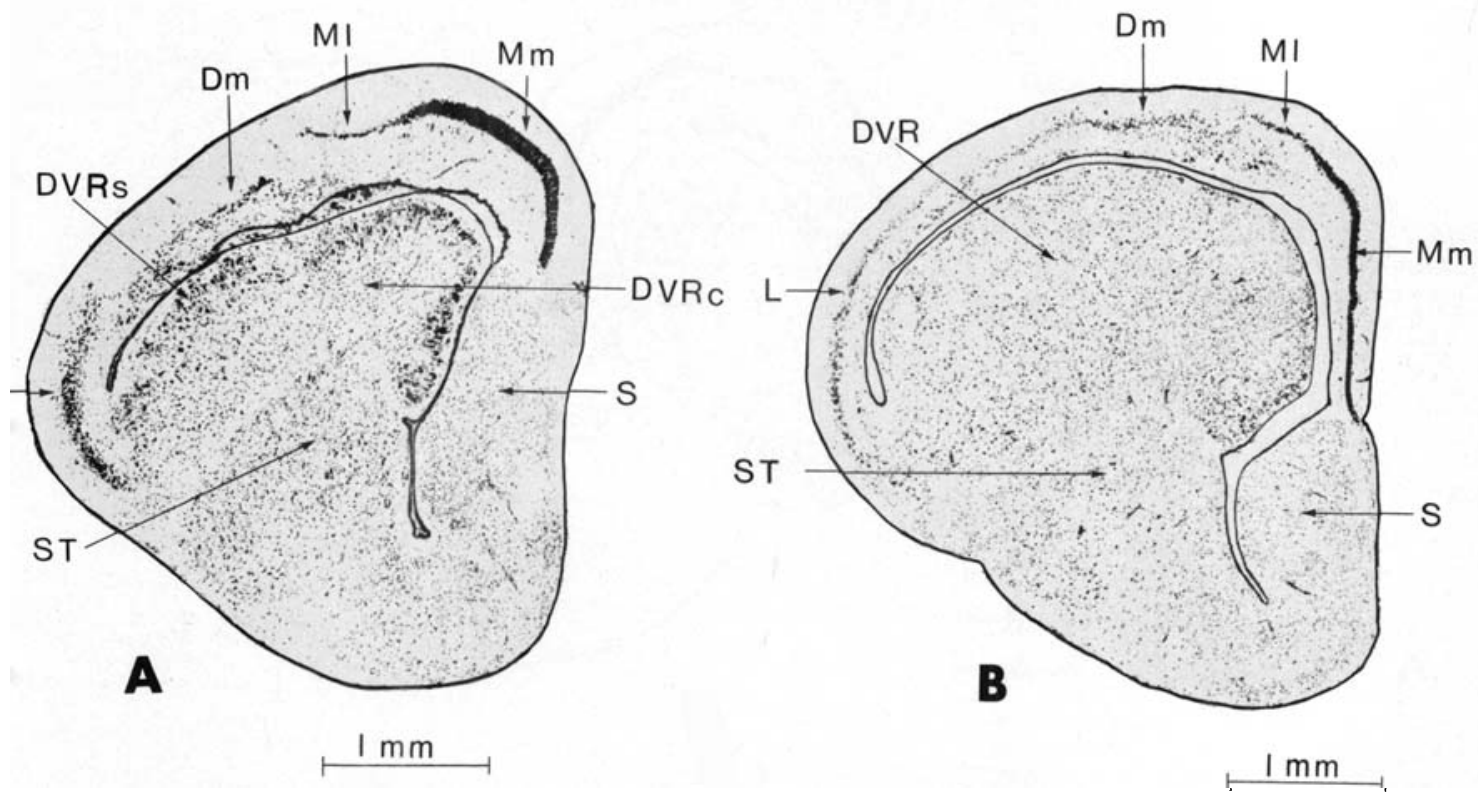

Fig. 1 Representative cross sections of the telencephalons of Gekko gecko (A) and lguanai iguana (B), representing lizard types I and II, respectively. Note the greater degree of corticoid band development in the dorsal ventricular ridge of Gekko, as compared to lguana.

eye. Thus, comparison of the visual projections in geckos with those of other reptiles should allow a more accurate assessment of those characters which are generalized among reptiles as opposed to those characters which are specialized as a result of particular adaptive pressures.

\section{MATERIALS AND METHODS}

Unilateral enucleations of either the right or the left eye were carried out under sodium pentobarbital anesthesia (20 $\mathrm{mg} / \mathrm{kg}$ ) on 12 adult specimens of the lizard Gekko gecko. The retina was removed by suction cannula in order to preclude the possibility of damage to vessels in the vicinity of the optic chiasm. The number of animals examined and the survival times, indicated in parentheses, following surgery were as follows: 2(10), 3(14), $2(20), 1(31), 1(43), 1(54), 1(64)$ and $1(74)$. The animals were maintained at temperatures that ranged from $25^{\circ}$ to $35^{\circ} \mathrm{C}$. Also available as controls were a number of gecko brains that sustained lesions of the cerebellum, medulla, olfactory bulbs, or telencephalon. The animals were sacrificed under anesthesia by transcardial perfusion with normal saline followed by $10 \%$ non-buffered formalin. The brains were removed and fixed in $10 \%$ formalin for a minimum of one week prior to being embedded in either albumin-gelatin or egg yolk, frozen, and sectioned on a sliding microtome at 25 micra. Sections were stored in $2 \%$ formalin at $4^{\circ} \mathrm{C}$, and were processed with various modifications of the Nauta silver impregnation method. These modifications included procedure I of the Fink-Heimer method (67), the procedure of Ebbesson and Heimer (Ebbesson, '70b), and the Eager method (70). Adjacent sections were stained with cresyl violet. The normal anatomy of diencephalic and pretectal nuclei was studied with sections stained with cresyl violet and the Bodian method. The terminology of these nuclei follows that used in the green iguana (Butler and Northcutt, '73).

Appropriate sections of experimental brains were drawn with the aid of a Bausch and Lomb microprojector, and the degeneration was plotted on these drawings. Selected sections of the cresyl violet series were photographed on Kodalith Ortho film, type 3 , with a Leitz largeformat camera. 

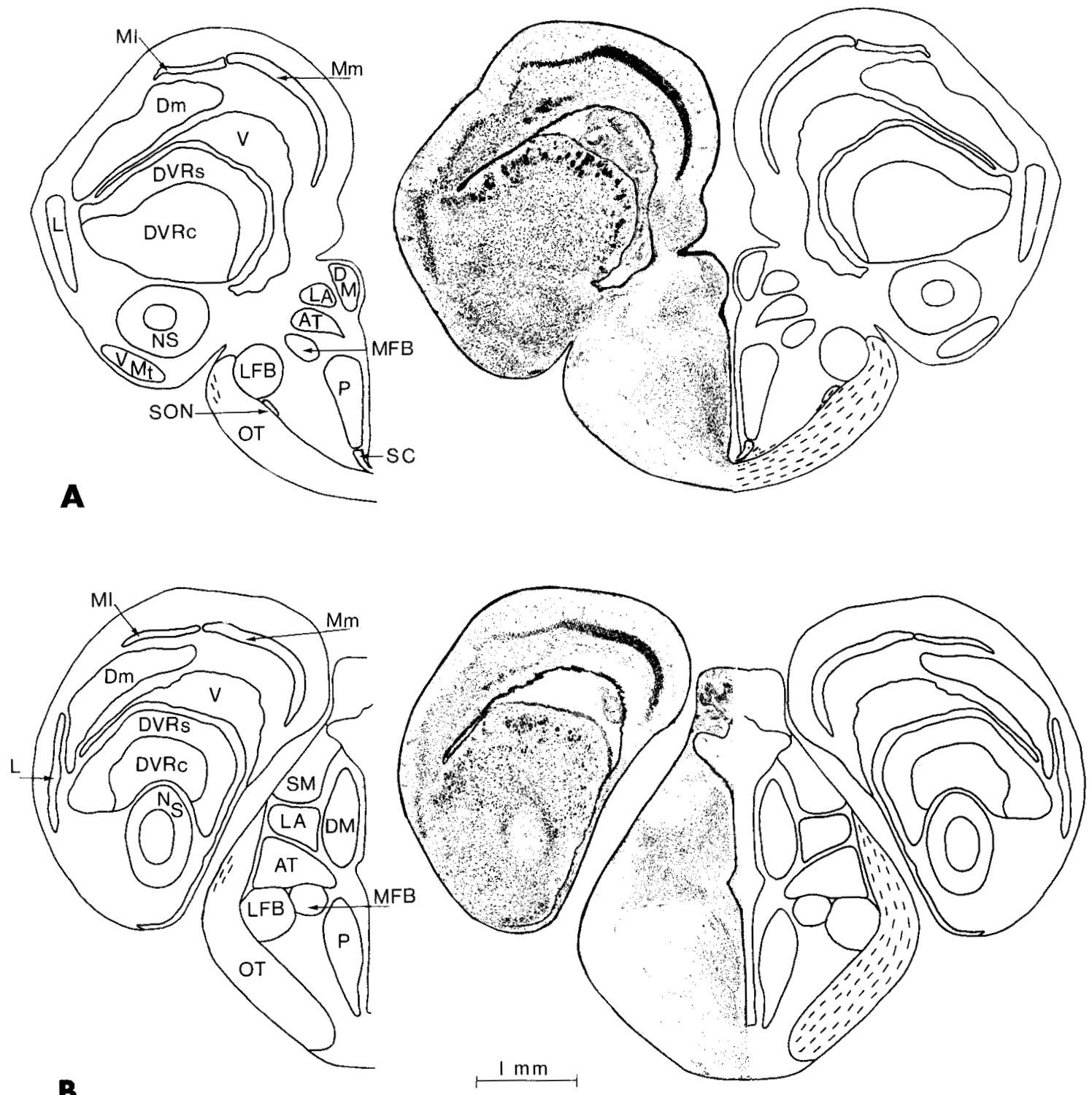

Fig. 2 Transverse section through the rostral diencephalon of Gekko gecko. In this and figs. 3-5, a Nissl preparation is shown in the center, the side ipsilateral to the removed retina is drawn on the left, and the contralateral side is drawn on the right. Degenerated fibers are represented by dashed lines and preterminal degeneration by stippling. The pattern of degeneration shown is charted for a case for which the survival time was 15 days. A: Transverse section through the level of the rostral portion of the diencephalon. B: Transverse section through the level of the stria medullaris.

RESULTS

Normal anatomy

In addition to differences in the morphology of telencephalic cell groups be- tween Gekko and Iguana, there are also a number of striking dissimilarities in the diencephalic and pretectal nuclei. Comparisons are made here with reference to the previously published account of the 

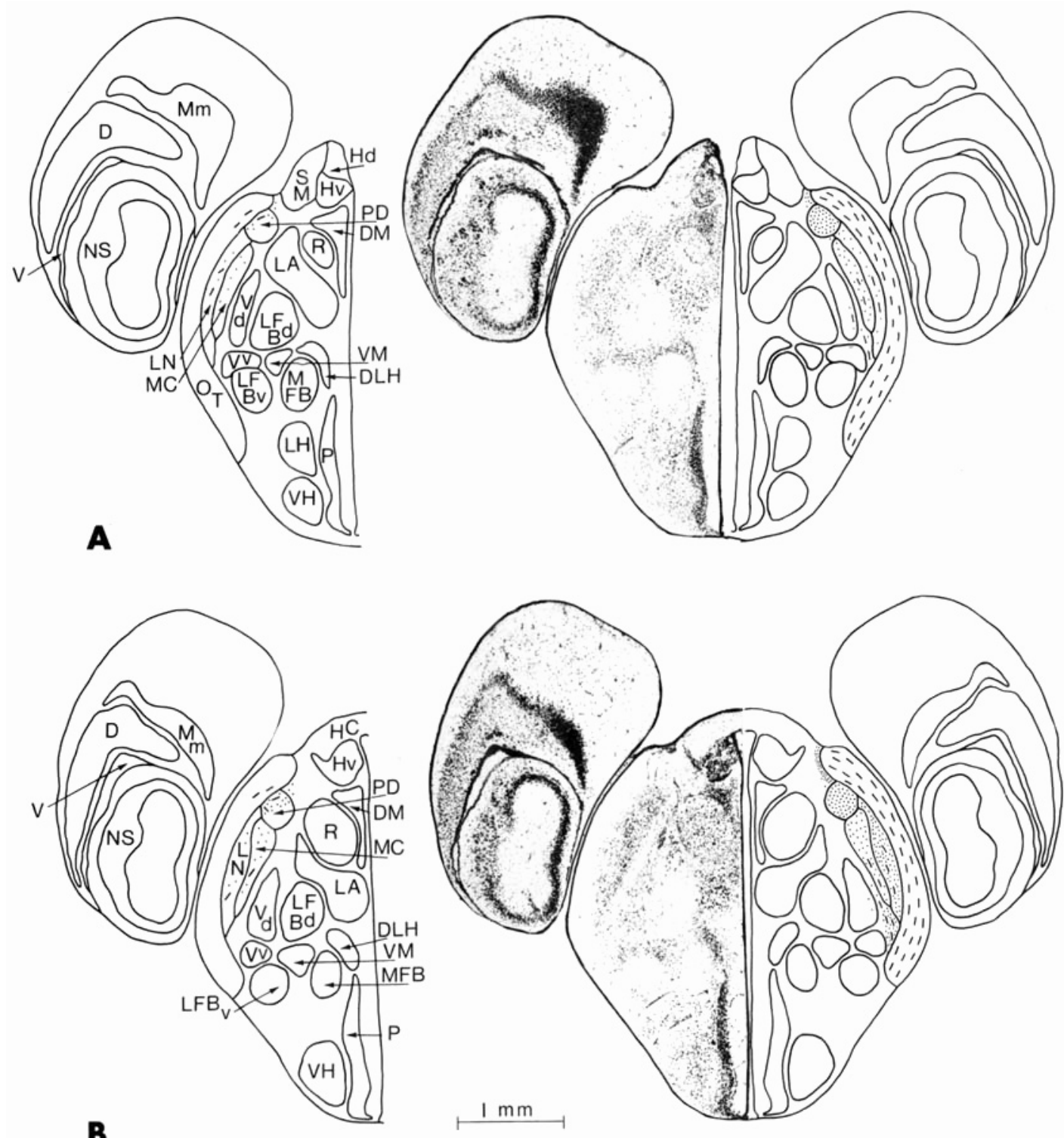

Fig. 3 A: Transverse section through the level of the rostral portion of nucleus geniculatus lateralis pars dorsalis. B: Transverse section through the level of the caudal portion of nucleus geniculatus lateralis pars dorsalis.

normal cytoarchitecture of Iguana (Butler and Northcutt, '73). In the rostral dorsal thalamus, nucleus dorsolateralis anterior (LA) appears similar to that in Iguana, being composed of a pars dorsomedialis containing medium sized cells with pale cytoplasm and a pars ventrolateralis containing larger cells scattered among fibers of the dorsal peduncle of the lateral forebrain bundle; this part of LA is greatly expanded in Gekko. This large celled portion expands laterally and ventromedially as it is traced caudally (fig. 3A), giving rise to two caudal poles (fig. 3B), the medial one occupying a position immediately rostral to nucleus medialis (fig. 4A). While 

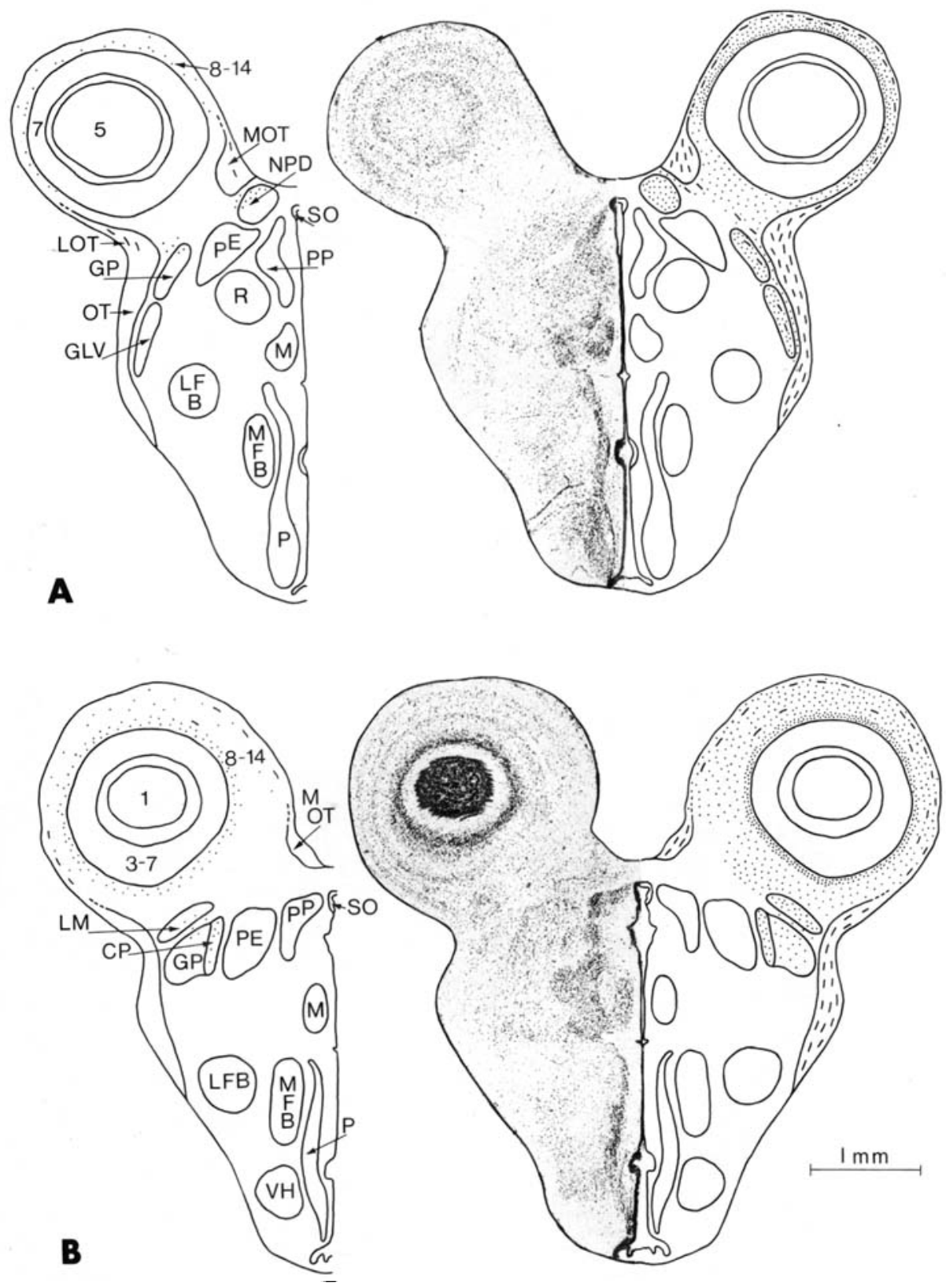

Fig. 4 A: Transverse section through the level of nucleus posterodorsalis. B: Transverse section through the level of nucleus lentiformis mesencephali.

the significance of this expansion of nucleus dorsolateralis is unknown, its increased size and position lateral to the rostral pole of nucleus rotundus (fig. 3A), could lead one to mistake it for rotundus.

Nuclei geniculatus lateralis pars dor- salis and pars ventralis in Gekko are similar in morphology to those in Iguana. The pars dorsalis is composed of a sphere of cells enclosing a core of neuropil, and the pars ventralis is composed of a cell plate and lateral neuropil (fig. 3A,B). Nu- 


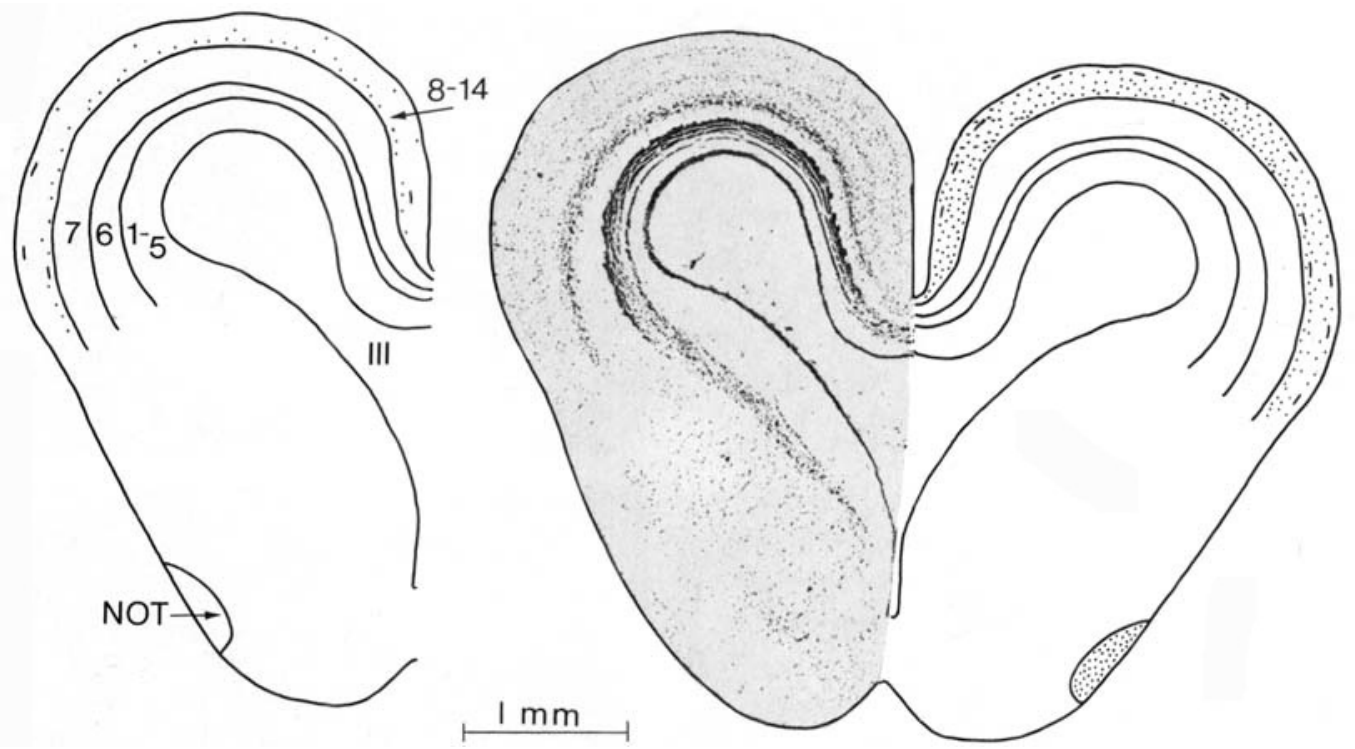

Fig. 5 Transverse section through the level of nucleus opticus tegmenti and the optic tectum

cleus dorsomedialis also corresponds closely to that described in Iguana, as do the nuclei of the ventral thalamus and hypothalamus. A small dense group of cells, appearing lateral to the lateral caudal pole of LA and dorsal to nucleus ventrolateralis pars dorsalis (fig. 3B), has not been named for the present as its identity is unknown.

The region ventral to the pretectum in Gekko, lying lateral to nucleus medialis (figs. 4A,B), remains unanalyzed due to its anatomical complexity and the lack of experimental data. Finally, the pretectal nuclei, such as nucleus lentiformis mesencephali and nucleus geniculatus pretectalis (fig. 4A), are less well differentiated than are those in Iguana.

\section{Experimental findings}

Following survival times of 10 days, argyrophilic debris is seen within the optic tract. However this debris is less dense and coarser than the debris seen among the nuclei and neuropil areas outside the optic tract (fig. 6B). Areas of high argyrophilic density that also possess fine particle size have been interpreted as preterminal and terminal degeneration. Following survival times of 15 days, argyrophilic debris within the optic tract is almost as dense as in the optic cellular targets, but the size of the particles is still larger than those found outside the optic tract. The argyrophilic reaction persisted in all material up to the longest survival time of 74 days (fig. $6 \mathrm{E}, \mathrm{F}$ ). However, the density of the argyrophilic debris decreased sharply with longer survival times (figs. $6 \mathrm{E}, 7)$.

Contralateral projections. Degenerated fibers of passage course caudally in the optic nerve to the optic chiasm, in which most fibers decussate. These fibers course dorsocaudally from the chiasm to the rostral part of the diencephalon where a few degenerated fibers course through the regions of the suprachiasmatic and supraoptic nuclei. The presence of fine argyrophilic debris suggests that optic fibers terminate in these nuclei; however, electron microscopy is needed to confirm this possibility (fig. 3A).

The contralateral retinal fibers continue to course dorsally along the lateral edge of the diencephalon and terminate densely in the pars dorsalis (PD) and pars ventralis (GLV) of the lateral geniculate nucleus (figs. 3A,B; 6A,B). Terminal debris is uniformly dense throughout the region of the pars dorsalis. In the pars ventralis the degeneration is more dense in the medial 

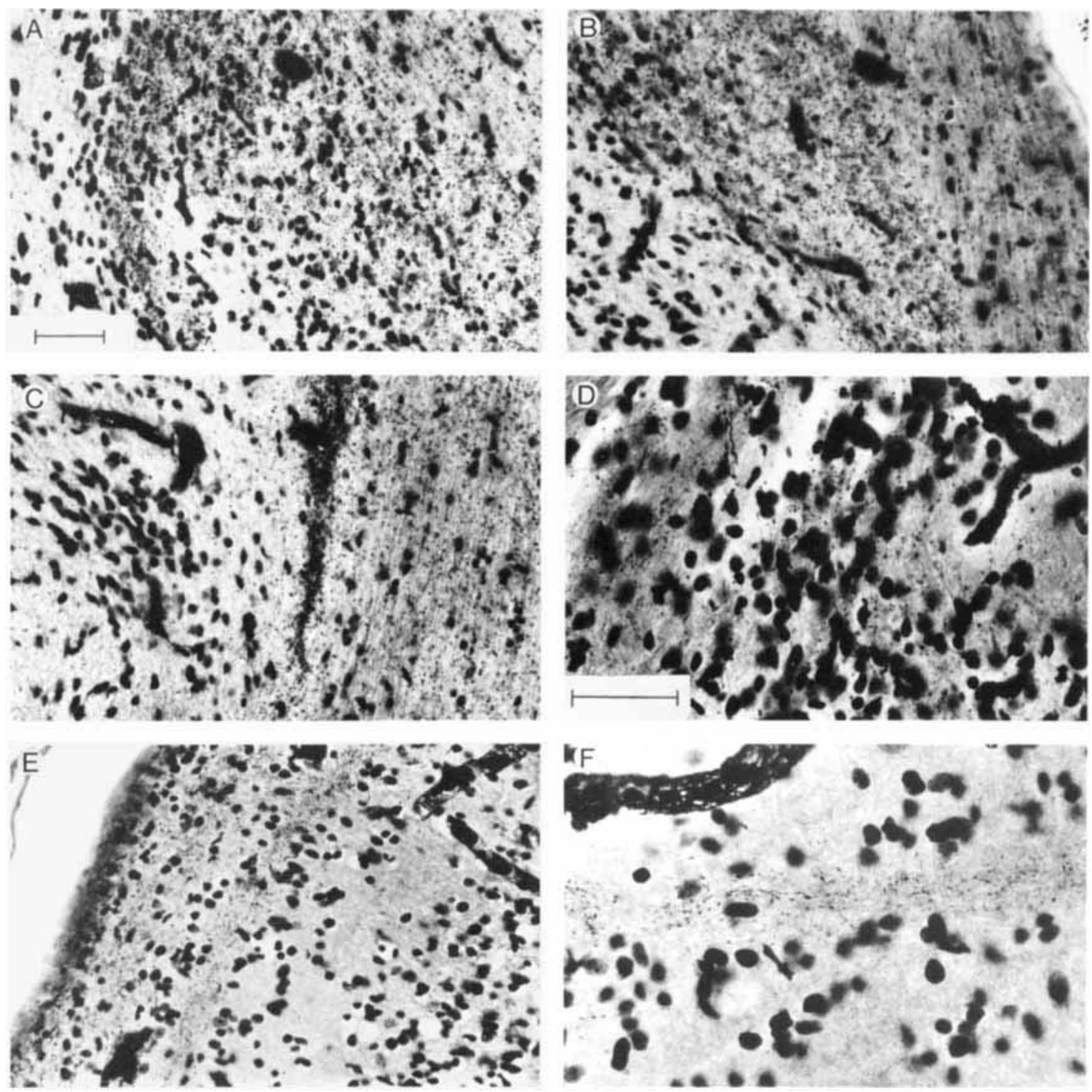

Fig. 6 Photomicrographs of degeneration following retinal removal in Gekko. A: Contralateral nucleus geniculatus lateralis pars dorsalis. B: Contralateral nucleus geniculatus lateralis pars ventralis. C: Contralateral nucleus ventrolateralis pars ventralis. D: Ipsilateral nucleus geniculatus lateralis pars dorsalis. E: Contralateral optic tectum. F: Ipsilateral optic tectum. Dorsal surface is toward top in all figures. Bar scale of A represents 50 micra. Magnification of $B, C$, and $E$ same as $A$. Bar scale of $D$ also represents 50 micra and magnification of $F$ is the same as D. Surgical survival times for A-D were 10 days; $E$ and $F$ were 74 days.

cell plate than in the lateral neuropil. Degenerated fibers and argyrophilic debris were also seen in our material in nucleus ventrolateralis pars ventralis ( $\mathrm{Vv}$ in figs. $3 \mathrm{~A}, \mathrm{~B} ; 6 \mathrm{C})$.

At rostral pretectal levels, degenerated fibers were traced dorsomedially through the pretectal nuclei (fig. 4A). Terminal debris is present among the large cells of nucleus lentiformis mesencephali (LM), in the poorly defined medial cell plate and lateral neuropil of nucleus geniculatus pretectalis (GP), and throughout nucleus posterodorsalis (NPD). Terminal degen- 

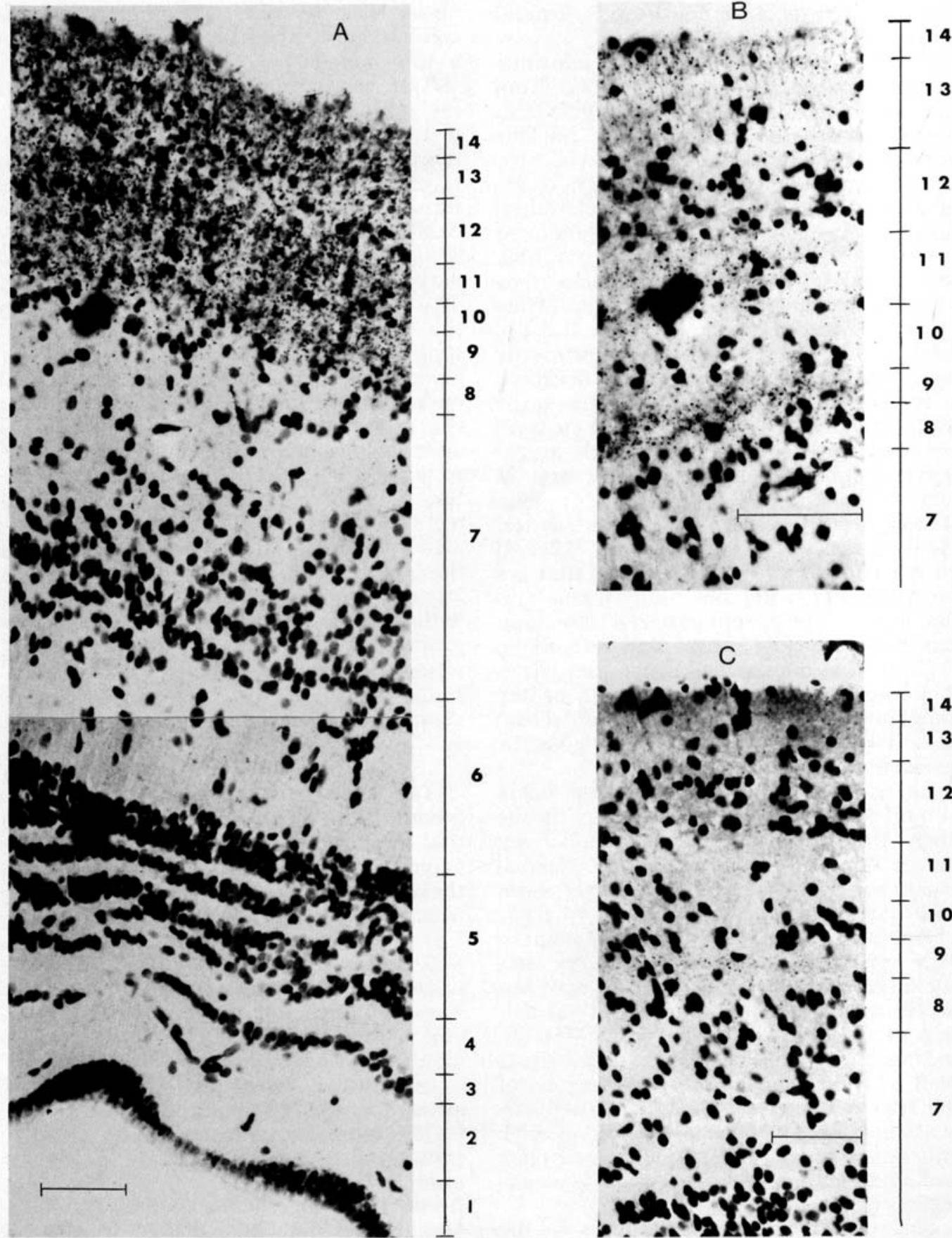

Fig. 7 Photomicrographs of degenerating optic fibers and terminals in the optic tecta following retinal removal in Gekko. A: Contralateral optic tectum with degenerating debris confined to the superficial layers. Surgical survival time 15 days. Note the sparseness of degenerating fibers in the dorsal half of layer 12. B: Contralateral optic tectum after a survival time of 10 days. Degeneration is primarily confined to layers 8,11 and 13 and is believed to represent terminal fields. C: Ipsilateral optic tectum of the same surgical case as 7B demonstrating the degenerating band in layers 8-9. All bar scales represent 50 micra. 
eration in GP is more dense in the caudal portion of the nucleus (fig. 4B).

Degenerated optic fibers which continue to course caudally after separating from the ventrolateral portion of the optic tract terminate in the contralateral nucleus opticus tegmenti (fig. 5).

The contralateral optic tectum is a site of dense terminal degeneration of retinal fibers (figs. 4, 5, 6D, 7A,B). Degenerated fibers enter the optic tectum from both the lateral and medial optic tracts (figs. $4 \mathrm{~A}, \mathrm{~B})$ and course in the superficial layers of the tectum (Layers 8-14 of Ramón, 1896). Layers 8, 11 and 13 are primarily composed of cell bodies and fine neuropil. It is in these layers that the earliest argyrophilic debris is located following survival times of ten days (fig. 7B). With longer survival times, coarser debris is seen in layers 9, 12 and 14 (fig. 7A). Bodian stained tectal sections cut in the sagittal plane demonstrate that layers 9, 12 and 14 are composed of fiber bundles that are in continuity with the optic tracts and that run in an antero-posterior direction. Based on the time course and size of the degenerating debris, we believe that layers 9,12 and 14 contain the axons of the ganglion cells coursing into the tectum and that layers 8,11 and 13 represent the terminal fields of these axons.

Layer 12 also appears to possess fibers of non-retinal origin as only part of the fibers in this layer degenerate following destruction of the retina (fig. 7A). Normal fibers were observed in this layer even with our longest survival time of 74 days.

Ipsilateral projections. A component of degenerated fibers in the optic nerve does not decussate in the optic chiasm but continues caudally in the dorsolateral portion of the ipsilateral optic tract (fig. 2). In the diencephalon, terminal debris is seen in the region of the pars dorsalis of the lateral geniculate nucleus, particularly in its dorsolateral portion (figs. $3 \mathrm{~A}, \mathrm{~B}, 6 \mathrm{E}$ ), and also sparsely in the medial cell plate and lateral neuropil of the pars ventralis (figs. 3A,B).

Some of the degenerated fibers in the ipsilateral optic tract continue caudally and give rise to sparse terminal debris in the pretectal nuclei - GP, LM, and NPD (figs. 4A,B). In NPD this debris is restricted to the lateral portion of the nu- cleus. It is, however, extremely sparse in comparison to the contralateral projection to this nucleus.

The remaining degenerated fibers in the optic tract enter the ipsilateral optic tectum via the medial and lateral optic tracts. Terminal debris is very sparse in layers $10-14$ but is more dense in the band formed by layers 8-9 (figs. 6F, 7C). This band of degeneration could be clearly recognized in animals with post-surgical survival times as short as ten days (fig. 7C). This same band was also visible in the animal with a post-surgical survival time as long as 74 days, as were the degenerating optic fibers in the contralateral optic tectum (figs. 6E,F). We believe that the argyrophilic debris in the ipsilateral optic tectum does represent a real optic projection because of the similarity in the time course of the degeneration in both tecta, because of the continuity of the debris from the optic nerve into the tectum, and because of the absence of this argyrophilic band in the control animals without optic lesions. However, due to the sparseness of the ipsilateral projections, other anatomical methods such as autoradiography and/or electron microscopy should strengthen these observations.

\section{DISCUSSION}

The lizard Gekko gecko is similar to other lizards which have been studied in that the retinal projections to nucleus geniculatus lateralis pars dorsalis of the thalamus are bilateral. The snakes Natrix (Armstrong, '51; Northcutt and Butler, '74), Thamnophis (Halpern and Frumin, '73), and Vipera (Repérant, '72) also have bilateral retinal projections to this nucleus. These findings support the idea that bilateral retinothalamic projections are a common feature of squamates.

In order to relate this information to other lineages of land vertebrates, the major living amniotic radiations must be considered. Four major distinct radiations exist formed by the Anapsida (turtles), Archosauria (crocodiles and birds), Lepidosauria (rhynchocephalians, lizards and snakes) and Synapsida (mammals). The sole surviving rhynchocephalian, Sphenodon, will not be discussed here as no experimental information is presently available. 
The bilateral retinothalamic projections found in squamates (lizards and snakes) occur commonly in members of only one other radiation, the synapsids, and have been described in numerous mammalian studies (e.g., Benevento and Ebner, '70; Campbell et al., '67; Laemle, '68; Tigges, '70). Sparse ipsilateral fibers of passage have been described in the turtle Emys (Kosareva, '67), the duck Anas (Bons, '69), and the crocodile Caiman sklerops (Burns and Goodman, '67). However, an anterograde degeneration study (Braford, '73) and a subsequent autoradiographic study (Braford and Northcutt, unpublished observations) have shown that the retinal projections in Caiman crocodilus are completely crossed. Thus, it generally appears that retinothalamic projections are entirely crossed in turtles (Knapp and Kang, '68a,b; Hall and Ebner, '70a) and in members of the archosaur radiation - the crocodiles (Braford, '73) and birds (Cowan et al., '61; Karten and Nauta, '68). Thus, ipsilateral retinothalamic fibers appear to be present in two amniotic radiations and absent in the two other major radiations. Given this distribution alone, it is impossible to determine whether an ipsilateral retinothalamic pathway was present ancestrally and independently lost in anapsids and archosaurs, or was absent ancestrally and is present in squamates and mammals as a result of parallelism. However, the presence of ipsilateral retinothalamic projections to a comparable dorsal thalamic nucleus in anuran amphibians (Scalia et al., '68) strongly suggests that this pathway was a generalized character present in ancestral land vertebrates, and that its absence in turtles, crocodiles, and birds is a secondary condition.

In mammals, the proportion of uncrossed optic tract fibers appears to be correlated with the degree of binocular overlap, and a role in stereoscopic vision has been postulated (Walls, '42). However, the original adaptive significance of uncrossed fibers may not have involved steropsis. Data of Kahmann, discussed by Walls, and summarized here in table 1 , show that the presence of ipsilateral retinothalamic projections is not correlated with the degree of binocular overlap in reptiles. Lizards and snakes represent extremes in binocular overlap, and have bilateral ret-
TABLE 1

Relation of measured binocular overlap to bilateral retinal projections

\begin{tabular}{lcc}
\hline & $\begin{array}{c}\text { Mean and range } \\
\text { of binocular } \\
\text { overlap }\end{array}$ & $\begin{array}{c}\text { Ipsilateral } \\
\text { projections } \\
\text { present }\end{array}$ \\
\hline Lizards & $20^{\circ}(14-32)$ & Yes \\
Crocodiles & $25^{\circ}(24-26)$ & No \\
Turtles & $30^{\circ}(18-38)$ & No \\
Snakes & $35^{\circ}(20-46)$ & Yes \\
\hline
\end{tabular}

inothalamic projections, whereas crocodiles and turtles, with intermediate degrees of overlap, do not. Thus, at present, the functional significance of partial decussation of retinothalamic fibers remains unclear.

While Gekko gecko resembles other squamates with regard to bilateral retinothalamic projections, it is strikingly different in that it also possesses bilateral retinotectal projections. The presence of ipsilateral retinotectal fibers has been thought to be a uniquely mammalian character, although an ipsilateral projection has recently been found to the ventrolateral rostral pole of the tectum in the lamprey Petromyzon (Northcutt and Przybylski, '73).

The presumed absence of such a projection in lizards does not appear to be due to the range of survival times used in other studies. Although terminal debris in the ipsilateral tectum is most pronounced in the gecko after long survival periods, it is observable after 10 days, which is within the range of survival times generally employed for reptilian material. There has, however, been a bias in the sampling of other species of lizards studied. With the exception of Armstrong's ('50) work on Lacerta using the Nonidez silver method, retinal projections have not been studied in any of the type I lizards. Furthermore, all previous studies have been done on diurnal lizards. Gekko gecko is a type I lizard, and it is nocturnal.

The only other non-mammal in which ipsilateral retinotectal projections have been described, the lamprey Petromyzon (Northcutt and Przybylski, '73), is active nocturnally. Members of the therapsid radiation of ancestral mammals are thought to have been nocturnal predators (Romer, '66), and it might thus be speculated that ipsilateral retinotectal projections have a 
role in nocturnal vision. Ablation studies of the tectum in reptiles (Bass et al., '73) and mammals, for example, Casagrande et al. (72), produce deficits in form discrimination. Additionally, similar studies in mammals show impairment of visual localization of objects after tectal lesions, for example, Schneider (70). Thus, it is possible that ipsilateral retinotectal projections may facilitate the location and/or identification of moving prey objects at low levels of illumination. Further studies, presently in progress, on other nocturnal and diurnal type I lizards may resolve this problem.

The finding that ipsilateral retinotectal projections are present in a saurian taxon raises the question of how wide-spread this pathway was ancestrally among land vertebrates. Ipsilateral retinotectal projections have not been reported in turtles (Kosareva, '67; Knapp and Kang, '68a,b; Hall and Ebner, '70a), crocodiles (Braford, '73; Braford and Northcutt, unpublished observations) or birds (Cowan et al., '61; Karten and Nauta, '68; Bons, '69), nor have they been described in the amphibians (Jakway and Riss, '72; Knapp et al., '65; Riss et al., '63; Scalia et al., '68) which have been studied.

From this distribution, based on presently available data, the most parsimonious interpretation is that the presence of ipsilateral retinotectal projections in some squamates and mammals is the result of parallelism; however, phylogenetic interpretations of this kind are only as valid as the sampling is representative of the total range of variation. To date, the sample of non-mammalian species studied is inadequate for a meaningful distributional evaluation of variation. For example, the statement that anuran amphibians do not possess ipsilateral retinotectal projections is based on a sample of three species representing only two of the twenty anuran families (Ranidae and Bufonidae), and these families represent two of the most specialized living anuran lineages. Therefore, with present data, it is virtually impossible to reach any valid conclusions regarding the origin and subsequent evolution of non-decussating retinotectal projections in non-mammalian taxa.

\section{ACKNOWLEDGMENTS}

The authors are pleased to thank Dr.
Mark Braford who followed the manuscript through several drafts and provided helpful suggestions, and Mr. Louis Martonyi for his expert assistance with the photography. Histological preparations were made by Mrs. Charlain Greene, Mrs. Neena N. Shah and Mr. Ronald G. Nicholes. This study was supported by National Institutes of Health Grant R01 N508417 an F10 NS2568-01 to R. G. N. and 5 RO1EY00154 to Dr. Sven O. E. Ebbesson.

\section{LITERATURE CITED}

Armstrong, J. A. 1950 An experimental study of the visual pathways in a reptile (Lacerta vivipara). J. Anat, 84: 146-167.

1951 An experimental study of the visual pathways in a snake (Natrix natrix). J. Anat, 85: 275-288.

Bass, A. H., M. B. Pritz and R. G. Northcutt 1973 Effects of telencephalic and tectal ablations on visual behavior in the side-necked turtle, Podocnemis unifilis. Brain Res., 55: 455-460.

Benevento, L. A., and F. F. Ebner 1970 Pretectal, tectal, retinal and cortical projections to thalamic nuclei of the opossum in stereotaxic coordinates. Brain Res., 18: 171-175.

Bons, N. 1969 Mise en evidence du croisement incomplet des nerfs optiques au niveua du chiasma chez le canard. Comptes Rendus Acad. Sci., 286: 2186-2188.

Braford, M. R., Jr. 1972 Ascending efferent tectal projections in the South American spectacled caiman. Anat. Rec., 172: 275-276.

1973 Retinal projections in Caiman crocodilus. Am. Zool., 13: 1345.

Burns, A. H., and D. C. Goodman 1967 Retinofugal projections of Caiman sklerops. Exp. Neurol., 18: 105-115.

Butler, A. B., and F. F. Ebner 1972 Thalamotelencephalic projections in the lizard Iguana iguana. Anat. Rec., 172: 282.

Butler, A. B., and R. G. Northcutt 1971 Retinal projections in Iguana iguana and Anolis carolinensis. Brain Res., 26: 1-13.

1973 Architectonic studies of the diencephalon of Iguana iguana Linnaeus. J. Comp. Neur., 149: 439-462.

Cairney, J. 1926 A general survey of the forebrain of Sphenodon punctatum. J. Comp. Neur., 42: $255-348$.

Camp, C, L. 1923 Classification of lizards. Bull. Amer. Mus. Nat. Hist., 48; $289-481$.

Campbell, C. B. G., J. A. Jane and D. Yashon 1967 The retinal projections of the treeshrew and hedgehog. Brain Res., 5: 406-418.

Casagrande, V. A., J. K. Harting, W. C. Hall, I. T. Diamond and G. F. Martin 1972 Superior colliculus of the treeshrew: A structural and functional subdivision into superficial and deep layers. Sci., 177: 444-446.

Citron, M. C., and L. H. Pinto 1973 Retinal image: larger and more illuminous for a nocturnal than for a diurnal lizard. Vision Res., 13: 873-876. 
Cowan, W. M., L. Adamson and T. P. S. Powell 1961 An experimental study of the avian visual system. J. Anat. (Lon.), 95; 545-563.

Durward, A. 1930 The cell masses in the forebrain of Sphenodon punctatum. Eng. J. Anat., $65: 8-44$.

Eager, R. P. 1970 Selective staining of degenerating axons in the central nervous system by a simplified silver method: spinal cord projections to external cuneate and inferior olive nuclei in the cat. Brain Res., $22: 137-141$.

Ebbesson, S. O. E. 1970a On the organization of central visual pathways in vertebrates. Brain Behav. Evol., 3: 178-194.

$1970 \mathrm{~b}$ The selective silver impregnation of degenerating axons and their synaptic endings in non-mammalian species. In: Contemporary Research Methods in Neuroanatomy, W. J. H. Nauta and S. O. E. Ebbesson, eds., Springer-Verlag, New York.

Fink, R. P., and L. Heimer 1967 Two methods for selective silver impregnation of degenerating axons and their synaptic endings in the central nervous system. Brain Res., 4: 369 -374

Hall, W. C., and F. F. Ebner 1970a Parallels in the visual afferent projections of the thalamus in the hedgehog (Paraechinus hypomelas) and the turtle (Pseudemys scripta). Brain Behav. Evol., 3: 135-154.

$1970 \mathrm{~b}$ Thalamotelencephalic projections in the turtle (Psendemys scripta). J. Comp. Neur., 140: 101-122.

Halpern, M., and N. Frumin 1973 Retinal projections in a snake, Thamnophis sirtalis. J. Morph., 141: 359-381.

Jakway, J. S., and W. Riss 1972 Retinal pro jections in the tigex salamander, Ambystoma tigrinum. Brain Behav. Evol., 5: 401 442 .

Karten, H., and W. J. H. Nauta 1968 Organization of retinothalamic projections in the pi geon and owl. Anat. Rec., 160: 373.

Knapp, H., and D. S. Kang 1968a The retinal projections of the side-necked turtle (Podocnemis uniflis) with some notes on the possible origin of the pars dorsalis of the lateral geniculate body. Brain Behav. Evol, $1: 369-404$.

$1968 \mathrm{~b}$ The visual pathways of the snap ping turtle, (Chelydra serpentina). Brain Behav. Evol., $1: 19-42$.
Knapp, H., F. Scalia and W. Riss 1965 The optic tracts of Rana pipiens. Acta neurol. scand., 414: 325-355.

Kosareva, A. A. 1967 Projection of optic fibers to visual centers in a turtle (Emys orbicularis). J. Comp. Neur., 130: 263-276.

Laemle, Lois Kalus 1968 Retinal projections of Tupaia glis. Brain Behav. Evol., 1: 473499.

Northcutt, R. G. 1970 The telencephalon of the western painted turtle, (Chrysemys picta belli). Ill. Biol. Monographs, 43, U. Ill. Press, Urbana. 1972 The teiid prosencephalon and its
bearing on squamate systematics. Program and abstracts of American Society of Ichthyologists and Herpetologists, 1972: 75-76.

Northcutt, R. G., and A. B. Butler 1974 Retinal projections in the Northern water snake, Natrix sipedon sipedon (L.). J. Morph., 142: 117-136.

Northcutt, R. G., and R. J. Przybylski 1973 Retinal projections in the lamprey Petromyzon marinus L. Anat. Rec., 150: 400.

Pritz, M. B. 1973 Connections of the alligator visual system: telencephalic projections of nucleus rotundus. Anat. Rec., 175: 416.

Ramón, P. 1896 Estructura del encéfalo del camaleon. Rev. Trimest. Micrográf., 1: $46-82$

Repérant, J. 1972 Étude expérimentale des projections visuelles chez la vipère (Vipera aspis). Comptes Rendus Acad. Sci., 275: 695-698.

Riss, W., H. Knapp and F. Scalia 1963 Optic pathways in Cryptobranchus allegheniensis as revealed by the Nauta technique. J. Comp. Neur., $121: 31-43$.

Romer, A. S. 1966 Vertebrate Paleontology, Third edition, U. Chicago Press, Chicago.

Scalia, F., H. Knapp, M. Halpern and W. Riss 1968 New observations on the retinal projection in the frog. Brain Behav. Evol., 1: 324-353.

Schneider, G. E. 1970 Mechanisms of functional recovery following lesions of visual cortex or superior colliculus in neonate and adult hamsters. Brain Behav. Evol., 3: 295-323.

Tigges, J. 1970 Retinal projections to subcor tical optic nuclei in diurnal and nocturnal squirrels. Brain Behav. Evol., 3: 121-134.

Walls, G. L. 1942 The Vertebrate Eye and Its Adaptive Radiation. Cranbrook Inst. of Sci. Bloomfield Hills, Michigan. 